\title{
SEISMOTECTONICS AND EARTHQUAKE RISK MACROZONING
}

\author{
IN NEW ZEALAND
}

\author{
R.P. Suggate*
}

\section{SYNOPSIS}

\begin{abstract}
Seismological and geological studies must be combined into a "seismotectonic" approach before better macrozones of earthquake risk can be designated. Since such zones were published as N.Z. Standard NZS 1900, 1965, pertinent studies have been made: on frequency of earthquake occurrence; on periodicity of faulting in different tectonic regions; and on the present geodetic strain rates. Integration of these and previous studies may result in agreed seismotectonic zoning, but the conversion to risk zones requires different types of decisions dependent on the assessment of the risks themselves and of the significance of differences of risk in relation to zone boundaries.
\end{abstract}

Regional differences in the probability of damage from earthquakes can be obvious, but the translation of these differences into some standard requirements that will gain professional and public confidence is no mean task. Key questions are: How is the distribution of future large shallow earthquakes to be judged? How far will the effects of these extend? Can earthquakes of the same magnitude be expected to have similar effects in all regions? What criteria can be used for boundaries of zones? How can the earthquake risks in the different zones - mazrozones (not microzones) - be expressed in terms of probability of danger from earthquakes? Do the differences in that probability justify differences in precautions?

There have been considerable advances in knowledge in some relevant fields in New Zealand since the paper "Tectonic and Earthquake Risk Zoning" by Clark et al (1965) included risk zones (Fig. 1) and since the issue of the New Zealand standard NZS 1900 (1965). Fig. 2 reproduces the zoning, unchanged from that of 1965, as given in the revised New Zealand standard NZS 4203 (1976). Those were produced at a time when there were considerable differences of opinion between geologists and seismologists, differences that did not ease the task of engineers and others who had the responsibility of producing the New Zealand standard. It is to be hoped that the differences are now less; certainly it is time to look again at the input necessary for judging the New Zealand standard, which satisfied neither geologist nor seismologist. The purpose of this paper is to review the current situation, not to put forward a new proposal.

The term "seismotectonics" is now in vogue. This can be taken to mean the integration of the evidence from seismicity and from tectonic deformation. There is nothing scientifically peculiar about attempting such an integration, but there are difficulties that stem, it can be contended, partly from the fact that studies of seismicity are essentially concerned with

* N.Z. Geological Survey, D.S.I.R., Lower Hutt. points (the positions of earthquakes) and studies of tectonic deformation are concerned with lines. Lines themselves have directions, and directions may indicate trends; with points the problem is to know which to join up to determine trends, although if the instrumental record is long enough, trends may become apparent, or areas of contrasting seismicity may show up.

Another difficulty is that of the contrasting time spans inherent in seismic and tectonic evidence. Seismic evidence ranges over only a few score years, it is not homogeneous because the number and locations of seismographs have changed over the years. Tectonic evidence on the other hand, covers many tens of thousands of years and could be substantially homogeneous over the last 20,000 years, but probably not more because of the partial destruction of the record by geological processes; it does, however, suffer from the problem of the difficulty of recognizing the evidence uniformly throughout the variety of regions of different topography and vegetation. Another contrast is between the ability of the seismic record to catalogue a wide range of earthquake magnitudes, and (making the normal assumption that in New Zealand surface faulting occurs by macroshifts and not by creep) the ability of surface faulting to record only the major earthquakes.

These differences do not prevent seismotectonic integration if seismologists and geologists all subscribe to a unifying theory that links present-day tectonic deformation with present-day seismicity. Plate tectonics may provide such a theory, but the New Zealand situation with respect to plate boundaries is far from simple. The seismotectonic integration could come about without such a theory, if the patterns of frequency of earthquake occurrance and of surface deformation were to coincide. The question of dissimilarities of patterns is noted later.

One contribution since the zoning given in the N.Z. Standard, in 1965, has been the application by Dick (1965) of 
extreme value theory to New Zealand earthquakes in an attempt to estimate the probable maximum magnitudes of earthquakes within specified regions and periods of time. The use of this theory, in relation to earthquakes, has been severely criticized by Knopoff and Kagan (1977) as giving unacceptably large probable errors in determination of maximum magnitudes, $b$ values and return times. These authors do, however, suggest that the use of maximum likelihood methods, would be significantly better. Eiby (1971) has applied maximum likelihood to calculate frequency of earthquakes, and $b$ values, in New Zealand, but only in two major regions, north and south of $43^{\circ} .45 \mathrm{~S}$, which extends roughly through Rangiora.

Frequency of earthquake occurrence and maximum magnitudes are only part of what is needed for macrozoning; the distance to which earthquake effects will extend is equally important. It is necessary to accept that attenuation of shaking is not uniform in all directions, as was recognized in the zoning context by Clark et a1. (1965, p. 120) before the 1968 Inangahua earthquake provided a particularly good example of elongation of felt intensities in the direction of the structural grain. Mathematical treatment of the variations has been made by Smith (1976).

It is now recognized by both geologists and seismologists in New Zealand that the likelihood of large earthquakes is greater in some places than in others - that the risk is likely to be greater. This does not automatically mean that macrozoning is justified, since it cannot automatically be assumed that the range of variation of risk is significant. Inferences from the basic data that must be studied in order to determine the variation of risk, need to be quantified as much as possible. Smith (1976) has made allowance for variation of MM value (the felt intensity) in 3 different regions for earthquakes of equal magnitude, in deducing MM values for earthquakes of different values of $M$ (magnitude) in the 3 regions. From historical, including instrumental records, he has calculated return periods for different intensities; an example is reproduced as Fig. 3. He admits, however, that his method "is likely to yield useful estimate for return periods of the order of the observation period or less". How much less it could be is not stated, and clearly if the conclusions can be confirmed or modified from other data, this is desirable in view of the shortness of the record.

Geologists would claim to be able to interpret their data from studies of Quaternary tectonic movements in a manner that can usefully contribute to producing the best seismotectonic answer, although clearly it is difficult to make the geological interpretation in quantitative terms. From knowledge of the distribution and trends of the tectonic movements, for example of active faults (Fig. 4), and from the knowledge that almost all major $(M>7.0)$ earthciuakes in New Zealand have been accompanied by surface deformation, tectonic zones (Fig. 5) have been suggested by Clark et al. (1965). However, new data has accumulated in the past 15 years, and Lensen (1974) has indicated that there are variations of periodicity of surface deformation (hence of major earthquakes) related to different predominant tectonic characteristics of different parts of the zones. Thus there is clearly a case for the revision of the tectonic zones. But whatever the modifications, the critical point is that geological evidence, because of its long time base, can be expected to help to smooth out the deficiencies resulting from the shortness of the seismic record. A prime example of the need to do this is the situation arising from the small number of earthquakes along the central parts of the Southern Alps and of the Alpine Fault. Few observers would doubt the active tectonism of that region from geological evidence, and however short the time for which zoning standards are set, few would exclude it from the highest risk zone.

It is the contrast between inferences from seismicity and from late Quaternary tectonics in south central South Island that results in the contrast between a pattern of the type shown by Smith and the pattern shown by Clark et al. This contrast cannot be eliminated by reconsideration of the effects of asymmetry of isoseismal patterns; nor can be it ascribed in inhomogenousness of the seismic record or of the geological record. It may result from the necessity of the seismologist to accept his record, short though it is, as being all he can draw conclusions from, in contrast to the preparedness of the geologist to extrapolate from what he can record through those areas where there are sound geological reasons for the non-existence, commonly through rapidity of erosion, of a comparable record.

The differences between the constraints imposed on seismologists and those imposed on geologists make it all the more important that an agreed approach should be found to the joint production of seismotectonic zoning. This can surely be done. But seismotectonic zoning is not earthquake risk zoning, which cannot be carried out until questions are answered such as "how can inferred differences in expected occurrence of shaking be translated into differences of risk?" and "what are the criteria for boundaries between areas of different risk?" Even after those are decided, it can be argued that macrozones of earthquake risk cannot adequately take into account the differences in the types of shaking from different earthquakes. And this is even more critical in the other major type of exercise in earthquake risk zoning - microzoning.

Altogether the task of zoning is so complicated that it might be questioned whether an answer of sufficient validity can be obtained. Only the clear knowledge that in any given period of time the chances of destruction or severe damage from an earthquake are significantly less in some parts of New Zealand than in others makes it worth examining the data to see whether macrozones might be delimited that would be rather more generally acceptable than the present ones.

\section{BIBLIOGRAPHY}

Clark, R. H., Dibble, R. R., Fyfe, H. E., Lensen, G.'J., Suggate, R. P. 1965. "Tectonic and Earthquake Risk Zoning." 
Transactions of the Royal Society of N.Z. General 1, 10: 113-126.

Dick, I. D. 1965. "Extreme Value Theory and Earthquakes". Proc. 3rd World Conference on Earthquake Engineering 1, III: 45-53.

Eiby, G. A. 1971. "The Frequency of Earthquake Occurrence in New Zealand." Journal of the Royal Society of N.Z. 1, 1: 79-82.

Knopoff, L., Kagan, Y. 1977. "Analysis of the Theory of Extremes as Applied to Earthquake Problems." Journal of Geophysical Research 82, 36: 5647-5657.

Lensen, G. J. 1974. "On the Nature of

Vertical Deformation and on the Frequency of Earth Deformation in General. "Tectonophysics 23: 391-406.

Lensen, G. J. 1977. "Late Quaternary
Tectonic Map of New Zealand. 1:2,000,000 (lst ed.)". N.Z. Geological Survey Miscellaneous Series Map 12. Department of Scientific and Industrial Research, Wellington, New Zealand.

Standards Association of New Zealand 1976. "Code of Practice for General Structural Design and Design Loadings for Buildings". N.Z. Standard 4203 .

Smith, W. D. 1976. "Statistical Estimates of the Likelihood of Earthquake Shaking Throughout New Zealand." Bulletin of the N.Z. National Society for Earthquake Engineering 9, 4: 213-221.

Paper received 31 January, 1979.

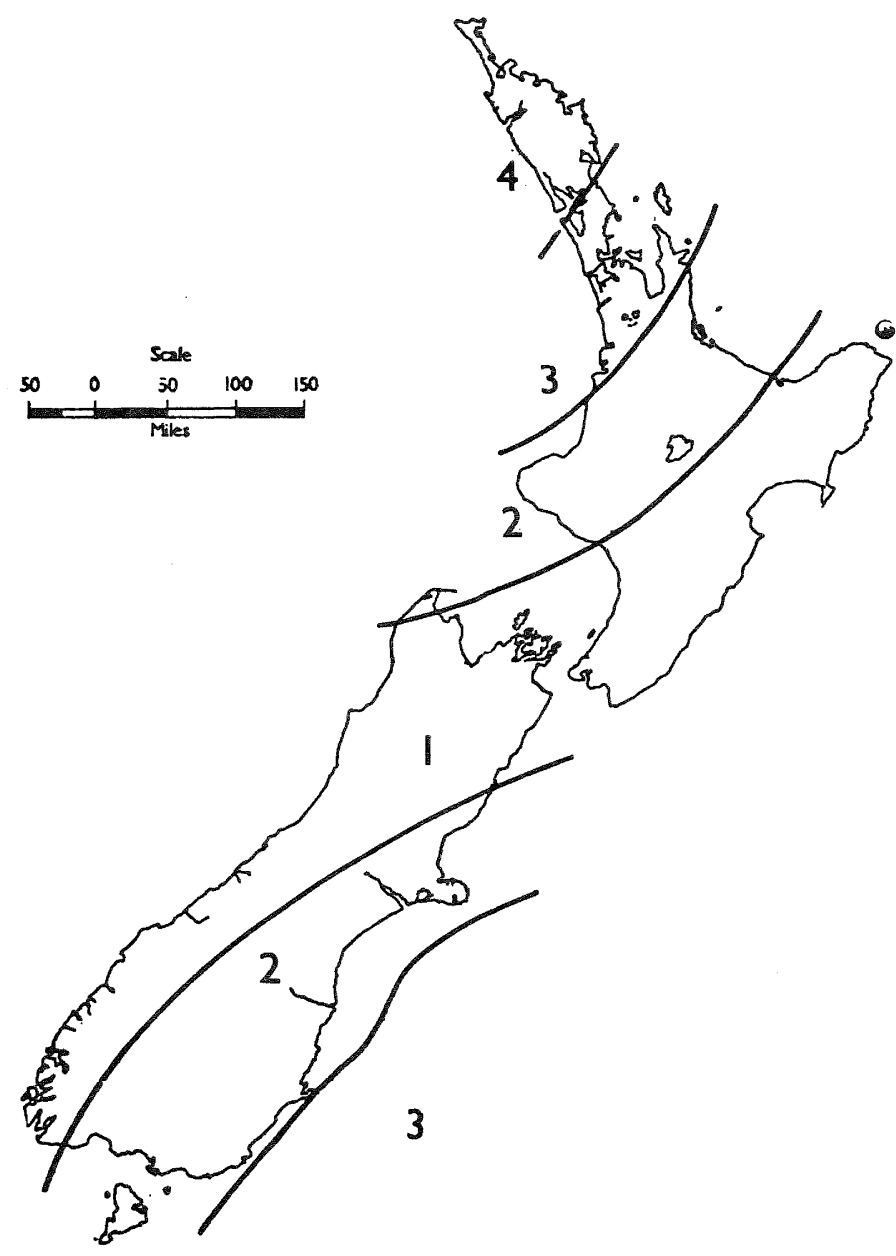

FIGURE 1: EARTHQUAKE RISK ZONES (FIG. 5 OF CLARK et al., 1965)
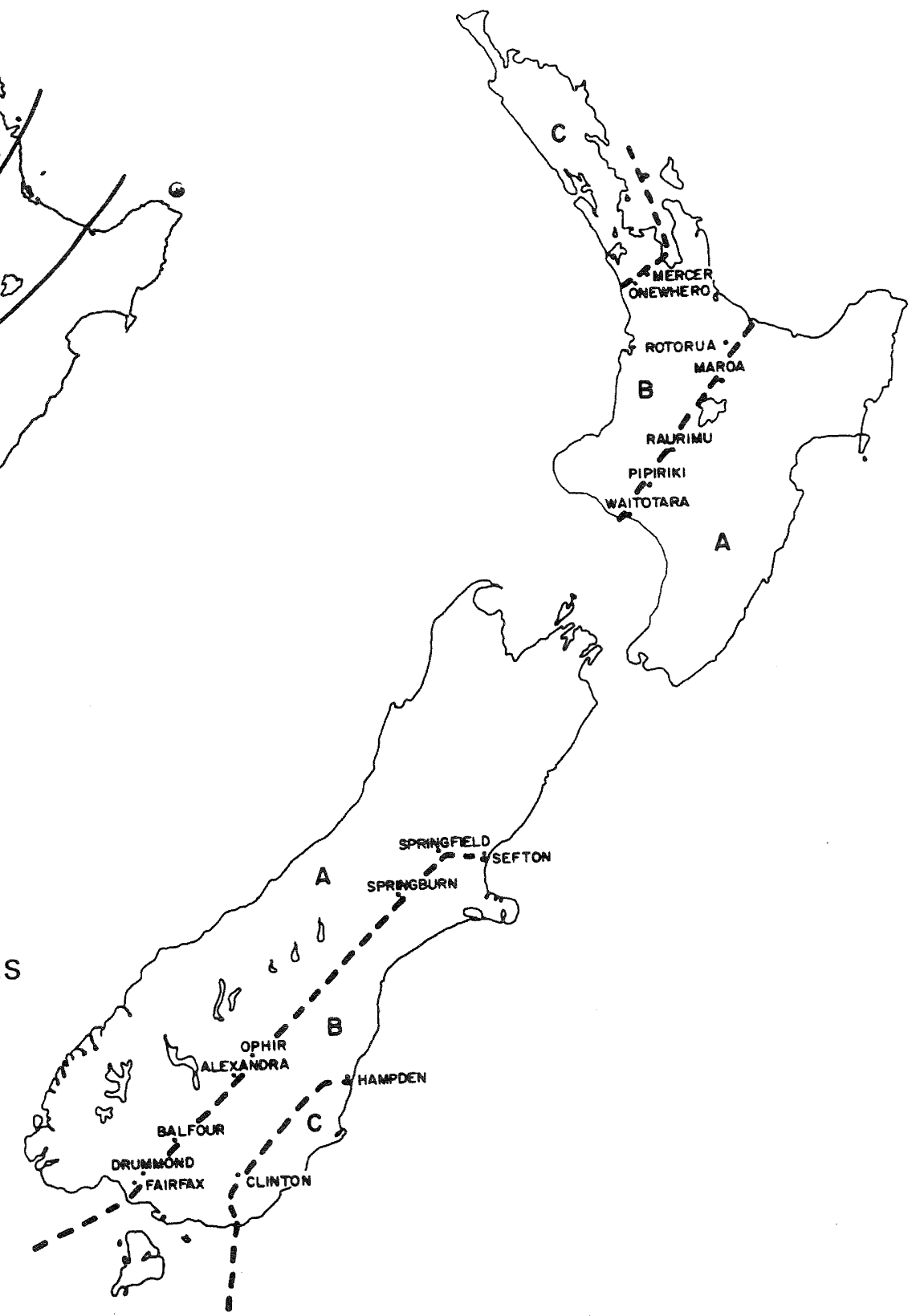

FIGURE 2: EARTHOUAKE RISK ZONES (FIGURE 4 OF N.Z. STANDARD 4203: 1976 


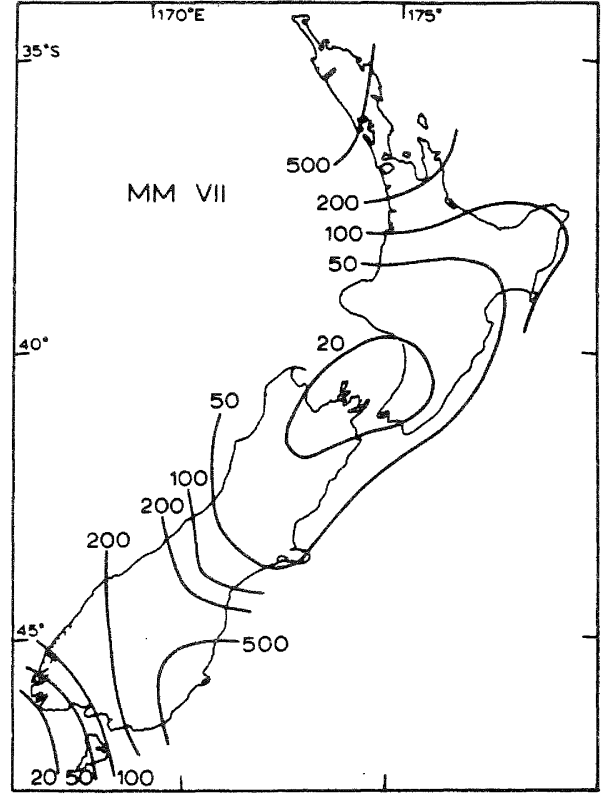

FIGURE 3: RETURN PERIODS IN YEARS FOR INTENSITY MM VII AND GREATER BASED ON THE OCCURRENCE OF LARGE EARTHQUAKES BETWEEN 1840 \& 1975 (FIG. 11 OF SMITH, 1976)

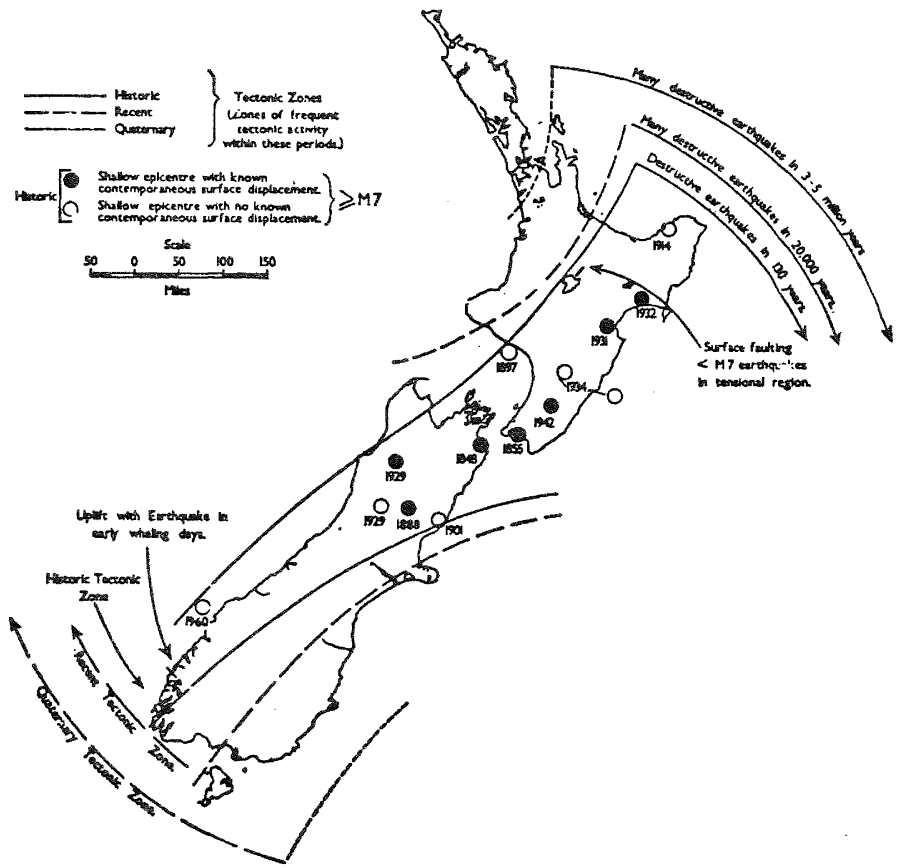

FIGURE 4: ACTIVE FAULTS (AFTER LENSEN, 1977)

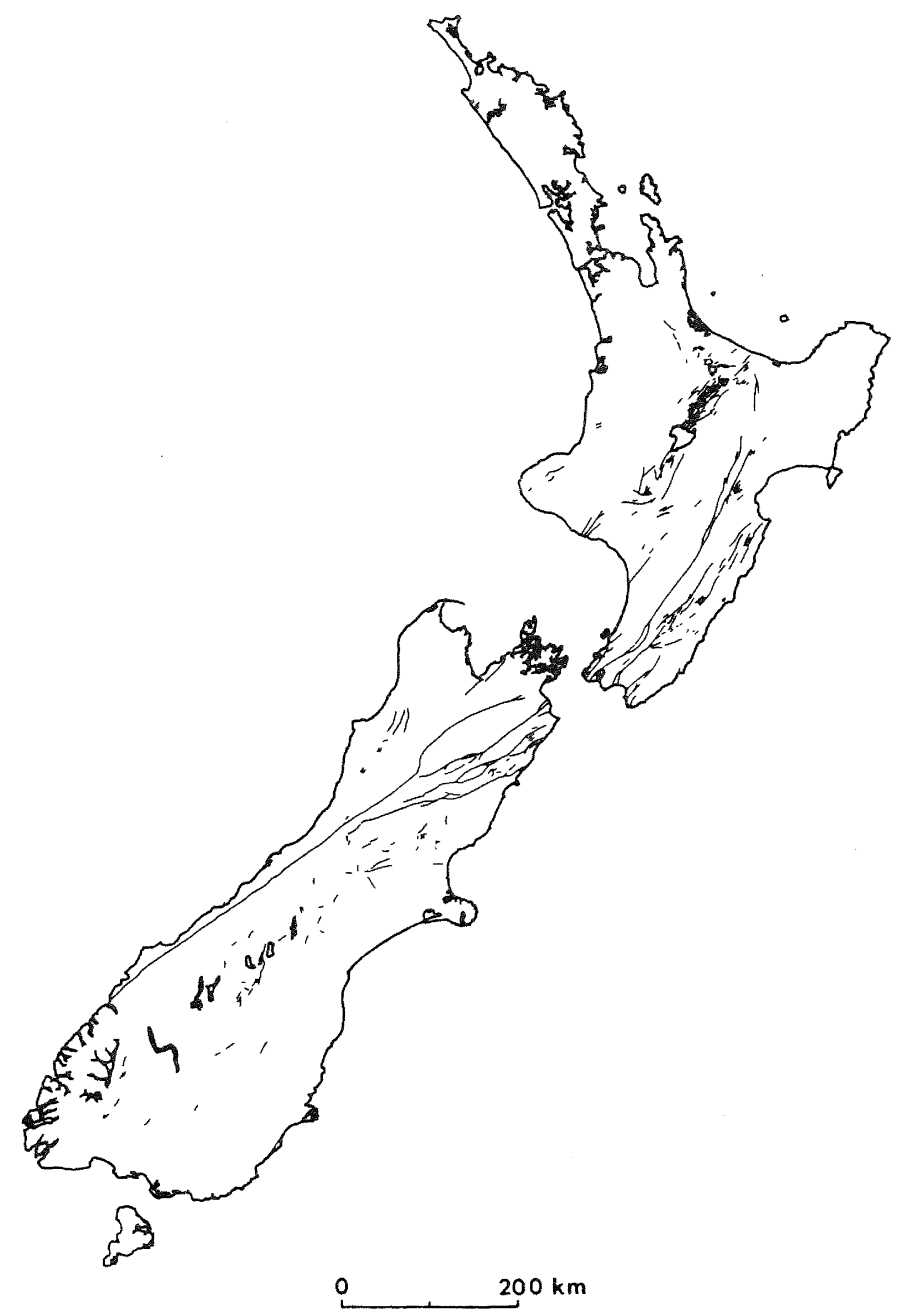

FIGURE 5: HISTORIC MAJOR EARTHQUAKES

AND TECTONIC ZONES (FIG. 3 OF CLARK et al., 1965) 